\title{
CHEMICAL COMPOSITION OF ESSENTIAL OILS FROM PANTELLERIA ISLAND AUTOCHTHONOUS AND NATURALIZED SPICES AND EVALUATION OF THEIR INDIVIDUAL AND COMBINED ANTIMICROBIAL ACTIVITIES
}

\author{
Raimondo Gaglio' ${ }^{1}$, Rosa Guarcello ${ }^{1 *}$, Marcella Barbera ${ }^{1}$, Ines Lommatzsch ${ }^{2}$, Tommaso La \\ Mantia $^{1}$, Alessio Ciminata ${ }^{1}$, Luca Settanni ${ }^{1}$ \\ ${ }^{1}$ Dipartimento Scienze Agrarie, Alimentari e Forestali, Università degli Studi di Palermo, Viale delle Scienze 4, \\ IT-90128 Palermo \\ ${ }^{2}$ Azienda Agricola Soleone srls, Via Venel/disé 35, 91017 Pantelleria (TP), Italy/ \\ *rosa.guarcello@unipa.it
}

https://doi.org/10.34302/crpjfst/2019.11.2.4

\begin{tabular}{|c|c|}
\hline Article history: & \multirow{11}{*}{$\begin{array}{l}\text { ABSTRACT } \\
\text { In this study, the antimicrobial activity of the essential oils (EOs) from } \\
\text { Origanum majorana L. and Rosmarinus officinalis L. growing in } \\
\text { Pantelleria (Sicily, Italy) were tested alone and in combination against } \\
\text { some prokaryotic and eukaryotic food-borne pathogens. The chemical } \\
\text { composition of the EOs as well as the minimum inhibitory concentrations } \\
\text { (MIC) against the most sensitive strains were also determined. Both EOs } \\
\text { showed interesting antimicrobial effects against all bacteria and yeasts } \\
\text { tested. MIC was in the range } 1.25-2.50 \mu 1 / \mathrm{ml} \text {. Interestingly, } O \text {. majorana } \\
\text { was particularly rich in thymol acetate, while carvacrol was present at very } \\
\text { low percentages. Also } R \text {. officinalis EOs composition was different from } \\
\text { rosemary collected in different areas, as being particularly rich in } \\
\text { caryophyllene. Furthermore, the antimicrobial activity of the combination } \\
\text { of } O \text {. majorana and } R \text {. officinalis EOs indicated their potential as food } \\
\text { biopreservatives. }\end{array}$} \\
\hline Received: & \\
\hline 28 November 2018 & \\
\hline Accepted: & \\
\hline 1 May 2019 & \\
\hline Keywords: & \\
\hline Chemical composition; & \\
\hline Essential oils combination; & \\
\hline Origanum majorana; & \\
\hline Rosmarinus officinalis; & \\
\hline Foodborne pathogens. & \\
\hline
\end{tabular}

\section{Introduction}

Spices are widely used in different countries of the Southern Europe and North Africa because of their aromatic, nutritional and antioxidant properties (Pezzani et al., 2017). Among the aromatic plants, marjoram and rosemary belong to the Labiatae family (Lamiaceae) and play a key role in the Mediterranean cuisine and diet (Gurbuz et al., 2016). Almost $75 \%$ of the Origanum species are restricted to the eastern Mediterranean area; eleven species are present in Greece, five of which are found in Crete (Aligiannis et al., 2001). The presence of Origanum also occurs commonly throughout Asia, Europe, and northern Africa (Han et al., 2017). Members of this genus are extensively used in the flavoring and preservation of foodstuffs and alcoholic beverages (La Pergola et al., 2017). Similarly, rosemary is used worldwide for its antimicrobial and antioxidant activities, along with anti-inflammatory and anti-tumoral properties (Bajalan et al., 2017).

Recently, there is a growing interest in industry to replace synthetic chemicals by natural products extracted from aromatic plants showing bioactive properties. Among 
them, Rosmarinum officinalis is considered one of the most important sources of both volatile and non-volatile bioactive compounds (OjedaSana et al., 2013). Within the same family, the essential oils (EOs) extracted from wild and cultivated Sicilian Origanum majorana have been considered natural antimicrobials (Tuttolomondo et al., 2013). In addition, they could represent a successful approach to contain the rising of bacterial resistance to synthetic antimicrobial compounds (Pezzani et al., 2017).

However, the biological properties of EOs depend on their chemical composition, which is genetically determined and influenced by the geographical origin, ecological conditions, growth stage and extraction method (Gaglio et al., 2017). Recently, a wide range of biological interactions between the various components of EOs is acquiring attention for food preservation purposes. EOs mixtures show the advantage that reduce the negative impact on food sensory properties due to addition of large amounts of EOs from a single given species often required to contrast microbial development (Nikkhah et al., 2017). Several aspects of EOs combination have been studied (de Rapper et al., 2016) and reviewed (Kohiyama et al., 2015). However, only a few studies have been carried out on the combined effects of EOs (Nguefack et al., 2012; Nikkhah et al., 2017). Recently, Baj and co-workers tested the antioxidant properties of mixtures of EOs from Ocimum basilicum L., Origanum majorana L. and Rosmarinus officinalis L.

However the antimicrobial activity of the mixtures have not been investigated (Baj et al., 2018). To this purpose, no exhaustive reports are available on the EOs composition and the combined biological activity of $O$. majorana and $R$. officinalis from Pantelleria (TP, Sicily). Due to its position in the Mediterranean Sea, this island hosts aromatic plant species characterized by distinct chemical profiles of EOs. Secondary metabolite profiling may allow to acquire information on the origin, autochthonous and healthy properties of the studied spices.

Therefore, the present study was aimed to investigate on the in vitro antimicrobial properties of the EOs extracted from marjoram and rosemary species growing in Pantelleria Island, alone or in combination, against several worldwide food-borne microorganisms and to correlate the biological activities to their chemical composition.

\section{Materials and methods}

\subsection{Plant material and extraction of EOs} Origanum majorana $(65 \mathrm{Kg})$ and Rosmarinus officinalis $(65 \mathrm{Kg})$ grown respectively, naturalized and wild in Pantelleria (Sicily, Italy) were collected from Nikà area $\left(36^{\circ} 75^{\prime} \mathrm{N}, 11^{\circ} 98^{\prime}\right.$ E) and Satarìa area $\left(36^{\circ} 78^{\prime} \mathrm{N}, 11^{\circ} 95^{\prime} \mathrm{E}\right)$, respectively, in spring 2015. Origanum majorana (synonymous Majorana hortensis Moench) is explicitly indicated as cultivated in Pantelleria (Giardina et al., 2007) from ancient time and where now it is naturalized. In Italy it is considered archeophyte (a plant species which is non-native to a geographical region, but which was introduced in "ancient" times) (Celesti-Grapow and Accogli, 2010).

Rosmarinus officinalis is an important element of the Pantelleria vegetation (Gianguzzi, 1999). Plant specimens were deposited at Herbarium Mediterraneum Panormitanum [PAL], Italy, /Origanum majorana/109617 and /Rosmarinus officinalis/109618 and in Herbarium SAF at Department of Agricultural Food and Forest Sciences (N. SAF 54pl and 55pl) $(\mathrm{n}=10$ per species). The plants were kept in dry and cool conditions until extraction of EOs carried out by steam distillation through a 60-1 stainless steel extractor (Cucuzza Inox Impianti S.A.A., Grammichele, Italy).

\subsection{Chemical analysis of the EOs}

EOs from $O$. majorana and $R$. officinalis were analyzed by gas chromatography (GC) 
and mass spectrometry (MS) technique in order to determine their chemical profiles. To this purpose, a GC/MS system consisting of a GC instrument (Agilent 6890; Palo Alto, CA, USA) and a mass selective detector (Agilent $5975 \mathrm{c}$; Santa Clara, CA, USA) was used.

The column set was a capillary column Carbowax (30-m length, 0.25-mm internal diameter and 0.25-lm film thickness; Supelco, Milan, Italy). The operating conditions were as follows: $1 \mu \mathrm{l}$ of EOs was injected in the split ratio (1:50) mode at a temperature of $250{ }^{\circ} \mathrm{C}$. $\mathrm{GC} / \mathrm{MS}$ instrument operated at $70 \mathrm{eV}$ in the $\mathrm{EI}$ mode over the $\mathrm{m} / \mathrm{z}$ range $30-550$. Helium carrier gas flow was at $1 \mathrm{ml} / \mathrm{min}$ and the temperature of the oven was programmed from 40 to $230{ }^{\circ} \mathrm{C}$ at $4{ }^{\circ} \mathrm{C} / \mathrm{min}$ and then held isothermal for $50 \mathrm{~min}$; the injector temperature and the transfer line were set at $250{ }^{\circ} \mathrm{C}$. All measurements were carried out in triplicate.

The identification of the chemical compounds was achieved by matching the fragmentation patterns of the experimental mass spectra with the commercial library NIST05. The relative proportions of the individual components were expressed as percent peak areas normalization, with all relative response factors being taken as one.

\subsection{Microbial strains}

In order to test the inhibitory properties of $O$. majorana and $R$. officinalis EOs, several bacterial and yeast strains of food origin and belonging to the culture collection of the Agricultural Microbiology Unit of the Department of Agricultural, Food and Forest Science - University of Palermo (Italy) - were used as indicators. Among prokaryotes, Acinetobacter guillouiae, Bacillus cereus, Serratia grimesii, Hafnia halvei, Hafnia paralvei, Enterobacterludwigii, Listeria monocytogenes, Raoultella ornithinolytica, Stenotrophomonas maltophilia, Staphylococcus epidermidis, Staphylococcus haemolyticus, Staphylococcus warneri species were used. The strains Lactobacillus sakei LMG 2313 and Listeria innocua 4202 were also included as being highly sensitive. The eukaryotes strains included Aureobasidium pullulans, Candida intermedia, Candida parapsilosis, Candida zailades, Cryptococcus curvatus, Pichia fermentans, Rhodotorula glutinis, Rhodotorula mucilaginosa, Saccaromyces cerevisiae.

All bacteria were subcultured in Brain Heart Infusion (BHI) broth (Oxoid, Milan, Italy) incubated at $37{ }^{\circ} \mathrm{C}$ for $24 \mathrm{~h}$, with the exception of $L b$. sakei LMG 2313 and $B$. cereus that were cultured in de Man, Rogosa and Sharpe (MRS) (Oxoid) and Nutrient Broth (NB) (Oxoid), respectively, incubated at $30{ }^{\circ} \mathrm{C}$ for $24 \mathrm{~h}$. Yeasts were reactivated in Yeast Peptone Dextrose (YPD) medium (Oxoid) incubated at $30{ }^{\circ} \mathrm{C}$ for $24 \mathrm{~h}$.

\subsection{Antibacterial activity determination}

A cell density of approximately $10^{7}$ $\mathrm{CFU} / \mathrm{ml}$ of each strain was reached in the optimal growth substrate (BHI, MRS, NA or YPD) and EOs of $O$. majorana and $R$. officinalis were tested applying the paper disc diffusion method of Kelmanson et al. (2000) (Kelmanson et al., 2000), with the modification reported by Cruciata et al. (2018). Briefly, an agar base support (2\% [wt/vol] water agar) was overlaid with $7 \mathrm{ml}$ of the optimal soft agar $(0.7 \% \quad$ [wt/vol] $)$ medium, as indicated by the respective culture collection for each strain, previously inoculated with approximately $10^{7} \mathrm{CFU} / \mathrm{ml}$ of a given test organism. Sterile filter paper discs (Whatman no. 1) of a 6-mm diameter were placed on the surface of the double agar layer and soaked with $10 \mu \mathrm{l}$ of each EOs.

Additionally, a mixture of oregan and rosemary EOs at ratio 1:1 was tested. Sterile water was used as negative control, while streptomycin $(10 \% \mathrm{w} / \mathrm{v})$ and cycloeximide $(0.01 \% \mathrm{w} / \mathrm{v})$ represented the positive control for bacteria and yeast, respectively. The inhibitory activity was evaluated after incubation under proper growth conditions as described above. The diameters of the inhibitory halos around the paper discs were 
measured. The experiments were performed in triplicate.

\subsection{Minimum inhibitory concentration}

The strains showing the highest sensitivity (i.e. showing the highest diameter of the inhibition halo) to the screening assay were used for MIC calculation. The MIC was defined as the lowest concentration of EOs inhibiting visible growth after $24 \mathrm{~h}$ of incubation as an expression of EO antimicrobial performances. In particular, the EOs were, serially, 2-fold diluted in the optimal growth substrate and the agar disc diffusion method was employed to determine the sensitivity to each dilution of the EOs (NCCLS, 2002) (Militello et al., 2011). The culture medium without bacteria/yeast was used as negative control.

\section{Results and discussions}

3.1. Chemical composition of Origanum majorana EOs

A total of 29 constituents (Table 1) were identified in marjoram EOs and the main components were thymol acetate $(21.77 \%)$, 4-carvomenthenol (17.82\%) and $\gamma$-terpinene $(15.81 \%)$. The oil average yield of the collected rosemary and origanum was determined to be $2 \%$ and $1,5 \%$, respectively.

Table 1. Chemical composition of $O$. majorana and $R$. officinalis EOs. Results indicate mean percentage values of three measurements and are expressed as relative peak areas (peak area of each compound/total area of the significant and common peaks to all samples) $\mathrm{x} 100$.

\begin{tabular}{|c|c|c|c|c|}
\hline \multirow{2}{*}{ Chemical compound } & \multicolumn{2}{|c|}{ Origanum majorana } & \multicolumn{2}{|c|}{ Rosmarinus officinalis } \\
\hline & Retention time (min) & $\%$ & Retention time (min) & $\%$ \\
\hline \multicolumn{5}{|c|}{ Monoterpene hydrocarbons } \\
\hline b-phellandrene & 14.124 & 2.44 & - & - \\
\hline Camphene & - & - & 11.229 & 2.78 \\
\hline Carene & 13.71 & 5.97 & - & - \\
\hline Isosylvestrene & 19.335 & 2.48 & - & - \\
\hline Limonene & - & - & 14.127 & 2.02 \\
\hline Myrcene & 12.885 & 1.39 & 12.889 & 1.16 \\
\hline p-cimene & 13.991 & 2.81 & 13.994 & 1.85 \\
\hline Sabinene & 12.19 & 2.54 & - & - \\
\hline$\alpha$-phellandrene & 13.278 & 1.09 & - & - \\
\hline$\alpha$-pinene & 10.703 & 0.54 & 10.708 & 8.8 \\
\hline$\alpha$-terpinene & 16.123 & 1.91 & - & - \\
\hline$\alpha$-thujene & 10.498 & 0.72 & - & - \\
\hline$\gamma$-terpinene & 15.163 & 16.54 & - & - \\
\hline \multicolumn{5}{|l|}{ Oxygenated monoterpenes } \\
\hline 1.8 cineol (eucayptol) & - & - & 14.225 & 30.82 \\
\hline 4-carvomenthenol & 18.93 & 18.65 & 18.93 & 0.77 \\
\hline Borneol & - & - & 18.604 & 5.92 \\
\hline Bornyl Acetate & - & - & 22.059 & 0.81 \\
\hline Carvacrol & 20.594 & 0.31 & - & - \\
\hline d-camphor & - & - & 17.901 & 12.73 \\
\hline p-menth-2-en-1-ol & 17.219 & 0.41 & - & - \\
\hline Sabinene Hydrate & 15.487 & 0.3 & - & - \\
\hline
\end{tabular}




\begin{tabular}{|l|l|l|l|l|}
\hline Thymol & 20.857 & 1.75 & - & - \\
\hline Thymol Acetate & 22.246 & 22.77 & - & - \\
\hline$\alpha$-terpineol & 19.335 & 2.37 & - & - \\
\hline Diterpenes & & & & \\
\hline Cembrene & 38.38 & 3.48 & - & - \\
\hline & & & & \\
Sesquiterpenes & & & & \\
\hline Cadinene & - & - & 24.356 & 0.37 \\
\hline Caryophyllene & 25.613 & 5.68 & 25.615 & 14.71 \\
\hline Guaiene & - & - & 27.492 & 0.74 \\
\hline Valencene & - & - & 26.102 & 0.43 \\
\hline$\alpha$-calacorene & - & - & 28.639 & 0.39 \\
\hline$\alpha$-copaene & 28.154 & 0.26 & - & - \\
\hline$\alpha$-cubebene & - & - & 24.473 & 1.61 \\
\hline$\alpha$-humulene & 26.469 & 0.6 & 26.469 & 1.8 \\
\hline$\beta$-bisabolene & 27.78 & 3.77 & 27.776 & 0.51 \\
\hline$\beta$-cadinene & 27.026 & 0.25 & 27.026 & 1.73 \\
\hline$\beta$-cubebene & 27.153 & 1.71 & 27.945 & 1.71 \\
\hline & & & & \\
Others & & & & - \\
\hline Bicyclogermanene & 27.537 & 3.75 & - & - \\
\hline Unknow & 16.555 & 0.72 & - & - \\
\hline Unknow & 21.198 & 0.83 & - & - \\
\hline Unknow & 23.44 & 0.33 & - & 4.38 \\
\hline Unknow & - & - & 28.157 & 1.62 \\
\hline Unknow & - & - & 29.613 & 2.34 \\
\hline$\alpha$-ionone & - & - & 19.335 & \\
\hline & & & & \\
\hline
\end{tabular}

The last component has been reported as a precursor of carvacrol (Tongnuanchan and Benjakul, 2014) and it is one of the major chemical compound of EOs extracted from different Origanum species and subspecies, including O. vulgare (Sezik et al., 1993), Origanum scabrum (Demetzos et al., 2001) and O. majorana (Jan et al., 2018). Similarly, 4-carvomenthenol (also known as 4-terpineol) was found as one of the major components of O. majorana (Baj et al., 2018; Busatta et al., 2017).

As reported in the literature, a number of oregano species are categorized by the presence of two main chemotypes, thymol and carvacrol. Another intermediate type would contain high content of two monoterpene hydrocarbons, $\gamma$-terpinene or p-cymene. Nevertheless, some species were found to contain high levels of linalool and other monoterpenes and sesquiterpenes (Baj et al., 2018). Moreover, marjoram main EOs also include the bicyclic monoterpene cissabinene hydrate and sabinene (Busatta et al., 2017), while the phenolic monoterpene carvacrol, arising from the "cymyl" pathway, is not a typical feature of this spice, as confirmed by our data (carvacrol $0.30 \%$ ). Similarly, thymol and thymol acetate are not generally present at high yield in marjoram EOs (Baj et al., 2018; Busatta et al., 2017; Jan et al., 2018). According to the literature, $O$. majorana from Pantelleria Island EOs contain oxygenated monoterpenes (44.61\%), 
monoterpene hydrocarbons (34.95\%), sesquiterpenes (11.75\%), diterpens (3.48\%) and other compounds (5.46\%). Surprisingly, despite literature data, O. majorana EOs from Pantelleria showed a very low percentage of sabinene $(2.42 \%)$ and sabinene hydrate $(0.29 \%)$.

These results indicated that $O$. majorana from Pantelleria is a thymol/terpinene-4-ol rich chemotype (Sellami et al., 2009). Thus, O. majorana is chemotypically different from the same species growing in other parts of Sicily (Tuttolomondo et al., 2013) and in other countries (Figuérédo et al., 2006; Sellami et al., 2009), which are characterized from different dominant constituents. Recently, EOs chemotypes have been defined on the basis of a single prominent monoterpene compound (La Pergola et al., 2017). However, they are often hard to compare when considering the whole monoterpene pattern, because of differences in composition according to the harvesting period, taxonomic classification, variety, age and part of the plant analyzed as well as geographical origin. In particular, the prevalent production of thymol and carvacrol is thought to depend on some external factors, such as climatic conditions, harvesting time, soil and/or the amount of water to which the plant is exposed (Kimura et al., 2006). The variation in the EOs composition of $O$. majorana from different origins could be attributed to both interactions between genetic (biotic) and environmental (abiotic) factors (Sellami et al., 2009).

\subsection{Chemical composition of Rosmarinus officinalis EOs}

According to the GC-MS data, 23 constituents (Table 1) were identified in $R$. officinalis EOs. The essential oil was mainly composed of oxygenated monoterpenes $(51.05 \%)$ and sesquiterpens (24\%). Within oxygenated monoterpenes 1,8 cineol, also known as eucalyptol (30.82\%), and d-camphor $(12.73 \%)$ were the major chemicals detected, while among sesquiterpens, caryophyllene
(14.71\%) was the most abundant compound. Among minor components, only $\alpha$-pinene exceeded $6 \%$ in $R$. officinalis EOs, followed by borneol. High yields of 1,8-cineole, caryophyllene and camphor have been reported for different rosemary samples from Pantelleria (TP), classified as cineoliferum (high content in 1,8 cineol) chemotype (Napoli et al., 2010). 1,8 cineol and $\alpha$-pinene have been reported as the major constituents of $R$. officinalis cultivars growing in different areas of Uruguay, southern Brazil (Dellacassa et al., 1999), and, along with camphor, in southern Spain (Tomei et al., 1995).

Boutekedjiret et al. (1998) investigated the essential oil from flowering aerial parts of $R$. officinalis collected in Algeria. More than $90 \%$ of the components were identified, with 1,8-cineole $(52.4 \%)$ and camphor $(12.6 \%)$ being the major components. Moreover, the chemical composition of $R$. officinalis EOs was similar to those found in the oils from Iran, India, Tunusia and Turkey, characterized by a high amount of camphor, eucalyptol, $\alpha$-pinene, $\beta$-pinene and borneol (Gurbuz et al., 2016). According to these authors, content, flavour notes and quality of rosemary EOs were influenced by the geographical location of the plants (ViudaMartos et al., 2007) and by the harvest time.

In particular, the concentration of 1,8 cineole was quite similar throughout the year, while the lowest concentrations of camphor and maximum concentrations of $\alpha$-pinene were observed in winter (Boutekedjiret et al., 1998). Interestingly, high yield of caryophyllene have not been previously reported for the EOs of $R$. officinalis collected in other regions (Napoli et al., 2010).

\subsection{Comparison of the chemical composition of EOs}

Comparing the chemical profile of the two EOs, we observed that eight compounds were common to both EOs, but differed in percentage. Interestingly, rosemary EOs was 
found to contain high levels of $\alpha$-pinene (8.80 $\%)$ and caryophyllene (14.71\%), while the same components were present at $0.51 \%$ and $5.42 \%$ in marjoram EOs. On the contrary, $O$. majorana and $R$. officinalis EOs contained 4carvomenthenol at $17.82 \%$ and $0.77 \%$, respectively. This characteristic distribution of the constituents of the two EOs constituted the rationale for our hypothesis of a combined antibacterial action. The amount of $\beta$ bisabolene, $\mathrm{p}$-cimene, $\beta$-cubebene, mircene and $\alpha$-humulene was in the range of 0.51-3.60 $\%$ in both EOs. Many of this EOs constituents have been considered by the FDA as Generally Recognized as Safe (GRAS) substances and are registered by the European Commission as food flavorings (Tongnuanchan and Benjakul, 2014).

\subsection{Antimicrobial activity of EOs}

There is a growing interest in assessing the antimicrobial effects of plant secondary metabolites against a range of foodborne pathogens, in order to counteract bacterial resistance to antibiotics (Bajpai et al., 2009). The application of natural products is of paramount importance for infection control and/or food preservation and to ensure consumers a safe, healthy, and nutritive food supply. Globally, all strains tested in this study (Table 2) showed sensitivity to both marjoram and rosemary EOs. Among Gram positive bacteria, S. haemolyticus ICE 182 and L. monocytogenes DHPS 179 were the most sensitive strains to $O$. majorana EOs, while $S$. epidermidis ICE 244 and L. monocytogenes DHPS 22 BO showed the most sensitivity to R. officinalis EOs. The high sensibility of Staphylococcus and Listeria species to EOs extracted from aromatic herbs is well known (Cao et al., 2009). Coagulase negative staphylococci used in the present study, such as $S$. epidermidis, $S$. haemolyticus and Staphylococcus warneri can be involved in nosocomial infections(Vuong and Otto, 2002), while $L$. monocytogenes is responsible for human disease deriving from food poisoning
(Swaminathan and Gerner-Smidt, 2007). Regarding Gram negative bacteria, $H$. paralvei 4G 53 and A. guilloue ICE24 growth was inhibited greatly by marjoram and rosemary EOs, respectively. $H$. paralvei belongs to the Enterobacteriacee family and is responsible for intestinal diseases, while Serratia and Acinetobacter species determine bloodstream infections (Wisplinghoff et al., 2004). Generally, EOs have been reported as slightly more active against Gram-positive than Gram-negative bacteria because of the complexity of their double-layer cell membrane. However, our results showed an antimicrobial action of $O$. majorana EOs against several Gram negative strains. Thus, our results support its use to counteract food poisoning caused by E. ludwigii and other species of clinical relevance tested in this study, such as the multidrug-resistant bacteria S. maltophilia or S. aureus (Kot et al., 2018).

The most sensitive strains were selected to calculate the minimum inhibitory concentration (MIC). MIC value for $\mathrm{O}$. majorana EOs was $1.25 \mu \mathrm{l} / \mathrm{ml}$ for $L$. monocytogenes DHPS 179 and $0.62 \mu \mathrm{l} / \mathrm{ml}$ for S. haemolyticus ICE 182, B. cereus ICE 170 and $H$. paralvei $4 \mathrm{G}$ 53. Regarding $\mathrm{R}$. officinalis EOs, MIC value was $1.25 \mu \mathrm{l} / \mathrm{ml}$ for both $L$. monocytogenes DHPS $22 \mathrm{BO}$ and $B$. cereus ICE 170. On the basis of these results, both the EOs presented a broad spectrum of antimicrobial activity. However, a sharper drop in the microbial growth was observed using $O$. majorana EOs, with the exception of L. monocytogenes DHPS $5 \mathrm{BO}$. The difference in the inhibitory effects of EOs extracted from marjoram and rosemary against different microorganisms has been related to their particular component profile (Tongnuanchan and Benjakul, 2014).

Therefore, the major effect of $O$. majorana EOs compared to $R$. officinalis from Pantelleria Island could be mainly due to the stronger antimicrobial activity presented by its preponderant constituents (Djeussi et al., 2013). Among the main 
constituents of $R$. officinalis, camphor has oxygen functions in its structure and these functions are known to increase the antimicrobial properties of terpenoids (Tongnuanchan and Benjakul, 2014).

A recent study, also referred to caryophyllene anti-oxidant, anti-inflammatory, anti-cancerous and local anesthetic effects (Klauke et al., 2014). On the other hand, 4terpineol, abundant in O. majorana, has been reported as an important antifungal and antibacterial agent (Djeussi et al., 2013; Pezzani et al., 2017) while thymol and carvacrol are the most active constituents against multiple foodborne pathogens (La Pergola et al., 2017). However, the acetylated form seemed to have low toxicity and enhanced biological effects. In particular, thymol and its synthetic derivative thymol acetate have shown antielmintic effect and antinociceptive activity (Angeles-Lopez et al., 2010). The strong antimicrobial activity of marjoram species from Mexico have been linked to the high thymol and phenolic monoterpene content (Ortega-Nieblas et al., 2011). Nevertheless, specific effects of thymol acetate on the microbial vitality/activity have not been reported yet. This characteristic chemical composition of Pantelleria $O$. majorana species may be responsible for its wide antimicrobial spectrum and support the use of this spices as food natural additive.

Table 2. Inhibitory activity of $O$. majorana (O.m.) and R. officinalis (R.o.) EOs. ${ }^{\text {a }}$-, no inhibition; \pm , low inhibition ( $<9 \mathrm{~mm}$ diameter); + , clear inhibition $(9-12 \mathrm{~mm}$ diameter); ++ , strong inhibition $(>13$ $\mathrm{mm}$ diameter). Results indicate the mean value of three independent assays.

\begin{tabular}{|l|c|c|c|l|}
\hline \multirow{2}{*}{ Strains } & \multicolumn{3}{|c|}{ Inhibition } & \multirow{2}{*}{ Source of isolation } \\
\cline { 2 - 5 } & O.m. & R.o. & O.m.+R.o. & \\
\hline Bacteria & & & & \\
\hline Acinetobacter guillouiae ICE 24 & ++ & ++ & ++ & Ice cubes \\
\hline Bacillus cereus ICE 170 & ++ & ++ & + & Ice cubes \\
\hline Enterobacter ludwigii 4G 145 & ++ & + & ++ & Ready to eat salad \\
\hline Hafnia alvei 4G 44 & ++ & + & ++ & Ready to eat salad \\
\hline Hafnia paralvei 4G 53 & ++ & + & ++ & Ready to eat salad \\
\hline L. monocytogenes DHPS 1 BO & ++ & ++ & + & Chopped meat \\
\hline L. monocytogenes DHPS 11 BO & ++ & ++ & ++ & Meat factory \\
\hline L. monocytogenes DHPS 12 BO & ++ & + & + & Ripened salami \\
\hline L. monocytogenes DHPS 129 & ++ & + & ++ & Human stool \\
\hline L. monocytogenes DHPS 13 BO & ++ & + & ++ & Gorgonzola cheese \\
\hline L. monocytogenes DHPS 131 & ++ & ++ & ++ & Human stool \\
\hline L. monocytogenes DHPS 133 & + & + & - & Human stool \\
\hline L. monocytogenes DHPS 179 & ++ & + & ++ & Salmon \\
\hline L. monocytogenes DHPS 180 & + & + & ++ & Ricotta cheese \\
\hline L. monocytogenes DHPS 182 & ++ & ++ & ++ & Ricotta cheese \\
\hline L. monocytogenes DHPS 184 & ++ & ++ & - & Rice salad \\
\hline L. monocytogenes DHPS 185 & + & + & ++ & Beef \\
\hline L. monocytogenes DHPS 186 & ++ & ++ & ++ & Mozzarella salad \\
\hline L. monocytogenes DHPS 187 & ++ & + & ++ & Roasted chicken \\
\hline L. monocytogenes DHPS 188 & ++ & + & ++ & Green salad \\
\hline & & & & \\
\hline
\end{tabular}




\begin{tabular}{|l|c|c|c|l|}
\hline L. monocytogenes DHPS 2 BO & ++ & + & ++ & Fresh salami \\
\hline L. monocytogenes DHPS 20 BO & ++ & ++ & ++ & Gorgonzola cheese \\
\hline L. monocytogenes DHPS 22 BO & ++ & ++ & ++ & Taleggio cheese \\
\hline L. monocytogenes DHPS 24 BO & ++ & ++ & ++ & Taleggio cheese \\
\hline L. monocytogenes DHPS 3 BO & + & + & + & Fresh salami \\
\hline L. monocytogenes DHPS 4 BO & ++ & + & + & Ripened salami \\
\hline L. monocytogenes DHPS 5 BO & + & ++ & + & Ripened salami \\
\hline L. monocytogenes DHPS 6 BO & ++ & ++ & + & Ripened salami \\
\hline L. monocytogenes DHPS 7 BO & ++ & ++ & ++ & Ripened salami \\
\hline Lactobacillus sakei LMG 2313 & ++ & + & + & Unknown \\
\hline Listeria innocua 4202 & ++ & + & + & Unknown \\
\hline Listeria monocytogenes ATCC 19114 & ++ & + & ++ & Animal tissue \\
\hline Raoultella ornithinolytica 4G 594 & ++ & + & ++ & Ready to eat salad \\
\hline Serratia grimesii 4G 954 & ++ & ++ & ++ & Ready to eat salad \\
\hline Staphylococcus epidermidis ICE 244 & ++ & ++ & + & Ice cubes \\
\hline Staphylococcus haemolyticus ICE 182 & ++ & + & ++ & Ice cubes \\
\hline Staphylococcus warneri ICE 20 & ++ & + & ++ & Ice cubes \\
\hline Stenotrophomonas maltophilia ICE 272 & ++ & + & + & Ice cubes \\
\hline & & & & \\
\hline Yeasts & & & & \\
\hline Auerobasidium pullulans AD201 & ++ & + & ++ & Wheat kernels \\
\hline Candida intermedia 4G137 & ++ & + & ++ & Ready to eat salad \\
\hline Candida intermedia 4G307 & ++ & + & ++ & Ready to eat salad \\
\hline Candida intermedia ICE86 & ++ & + & + & Ice cubes \\
\hline Candida parapsilosis ICE214 & ++ & + & ++ & Ice cubes \\
\hline Candida zailades 4G362 & ++ & + & ++ & Ready to eat salad \\
\hline Criptococcus curvatus ICE84 & ++ & ++ & ++ & Ice cubes \\
\hline Pichia fermentans 4G140 & ++ & + & + & Ready to eat salad \\
\hline Rhododotorula glutinis AD64 & ++ & ++ & ++ & Ice cubes \\
\hline Rhodotorula mucilaginosa ICE29 & ++ & ++ & ++ & Grape \\
\hline Saccaromyces cerevisiae GR1 & + & & \\
\hline
\end{tabular}

\subsection{Antifungal activity of EOs}

The development of natural protective agents against pathogenic fungi and yeasts causing food spoilage is currently in the focus of many research groups. Therefore, in the present investigation the antifungal activities of $O$. majorana and $R$. officinalis EOs was examined. Interestingly, both EOs showed marked antifungal activities against eleven yeasts, that appeared to be spices-dependent. All yeast growth was inhibited more markedly by marjoram than rosemary EOs. Both EOs showed antifungal action against pathogenic yeasts belonging to different genera including Candida, Aureobasidium and Rhodotorula.

Among them, $C$. parapsilosis has been commonly associated with blood, wound and tissue infections (Palmeira-de-Oliveira et al., 2009) while $A$. pullulans and $R$. glutinis, despite their importance in biotechnology, have emerged as opportunistic human pathogens (Najafzadeh et al., 2014; Nunes et al., 2013). Pichia fermentans, a spoilage yeasts belonging to the Saccharomycetaceae family, has been frequently isolated from orange juice and fermented foods (Qvirist et al., 2016). On the other hand the oleaginous yeast $C$. curvatus and 
S. cerevisiae are acquiring growing importance in food industry (Liu et al., 2017). To our knowledge, the effects of marjoram and rosemary EOs on the mentioned species have not been investigated elsewhere, with the exception of Candida, S. cerevisiae and Rhodotorula glutinis (Kunicka-Styczyńska, 2011; Palmeira-de-Oliveira et al., 2009; Tripathy, et al., 2017). In addition, the EOs obtained from O. majorana have shown antifungal activity against Aspergillus flavus and A. parasiticus (Palmeira-de-Oliveira et al., 2009; Tripathy et al., 2017).

Surprisingly, we observed that $C$. curvatus ICE84 and $S$. cerevisiae GR1 were the most sensitive strains to marjoram EOs (MIC 1.25 $\mu 1 / \mathrm{ml}$ ) and rosemary EOs (MIC $1.25 \mu \mathrm{l} / \mathrm{ml}$ ), respectively. As stated in the literature, $\alpha$ terpinene and other constituents of aromatic plant EOs affect ergosterol biosynthesis and sterol uptake, influencing yeast physiology (Parveen et al., 2004).

\subsection{Antimicrobial activity of EOs mixture}

The combined use of the EOs from $O$. majorana and $R$. officinalis was tested to inhibit the survival of all bacteria and yeasts strains reported above. Our results showed that the application of the EOs alone or in mixture (1:1) caused the inhibition of the growth of all tested strains, with the exception of $L$. monocytogenes DHPS 133 and DHPS 184. Only for these two strains an antagonistic effect of the combined application of EOs may be supposed.

Conversely, an enhanced antimicrobial effect was observed vs L. monocytogenes DHPS 180 and DHPS 185, suggesting an interactions between the components of the two EOs. The combined EOs reduced the diameter of the inhibition halos of all other strains. These results might be due to the use of sub-inhibitory amount of each EOs in the mixture. Moreover, it would seem reasonable that the combination of EOs possessing compounds with similar structures may show additive rather than synergistic effect. The occurrence of additive interactions of these EOs could be related to their similar composition possessing phenolics (carvacrol and thymol) as main compounds, suggesting a similar mechanism of action (De Azeredo et al., 2011). On the other hand, the increased antimicrobial activity caused by the mixture of these EOs could be partially explained considering the different compounds found for each EOs individually. Additive effects of mixture of EOs extracted from aromatic plant have been reported. However, increasing evidences indicate that the inherent activity of EOs may not depend exclusively on the ratio in which the main active components are present, but also interactions between these and minor constituents of the EOs. As an example, among hydrocarbons, p-cymene probably enables easier entrance of carvacrol into the cell membrane where it exerts its action. Moreover, the lipophilic properties and the characteristic functional groups of each component may influence the biochemical properties of the mixture (Hyldgaard et al., 2012).

In our study, O. majorana and $R$. officinalis EOs combined at sub-inhibitory concentrations were effective in inhibiting the growth and survival of pathogenic and spoilage microorganisms, although the underlying mode of action has to be better explored.

\section{Conclusions}

Experimental data indicated that $O$. majorana and $R$. officinalis EOs are effective against Gram positive and Gram negative bacteria and yeasts. The inhibitory activities of marjoram EOs were stronger than rosemary EOs. These properties could be partly due to the presence of some classes of compounds, such as monoterpene hydrocarbons and oxides, characteristics of the spices of Pantelleria Island. The fact that both $O$. majorana and $R$. officinalis EOs, alone or in combination, exhibited antimicrobial activities against the microorganisms studied supports their application in food industry. 


\section{References}

Aligiannis, N., Kalpoutzakis, E., Mitaku, S., Chinou, I.B. (2001). Composition and antimicrobial activity of the essential oils of two Origanum species. Journal of Agricultural and Food Chemistry, 49, 41684170.

Angeles-Lopez, G., Perez-Vasquez, A., Hernandez-Luis, F., Deciga-Campos, M., Bye, R., Linares, E., \& Mata, R. (2010). Antinociceptive effect of extracts and compounds from Hofmeisteria schaffneri. Journal of Ethnopharmacology, 131, 425432.

Baj, Tomasz, Baryluk, Andrew, \& Sieniawska, Elwira. (2018). Application of mixture design for optimum antioxidant activity of mixtures of essential oils from Ocimum basilicum L., Origanum majorana L. and Rosmarinus officinalis L. Industrial Crops and Products, 115, 52-61.

Bajalan, I., Rouzbahani, R., Pirbalouti, A.G., Maggi, F. (2017). Antioxidant and antibacterial activities of the essential oils obtained from seven Iranian populations of Rosmarinus officinalis. Industrial Crops and Products, 107, 305-311.

Bajpai, V.K., Al-Reza, S.M., Choi, U.K., Lee, J.H., Kang, S.C. (2009). Chemical composition, antibacterial and antioxidant activities of leaf essential oil and extracts of Metasequioa glyptostroboides Miki ex Hu. Food and Chemical Toxicology, 47, 18761883.

Boutekedjiret, C., Bentahar, F., Belabbes, R., Bessiere, J.M. (1998). The essential oil from Rosmarinus officinalis L. in Algeria. Journal of Essential Oil Research, 10, 680682.

Busatta, C., Barbosa, J., Cardoso, R. I., Paroul, N., Rodrigues, M., de Oliveira, D., de Oliveira, J.V., Cansian, R.L. (2017). Chemical profiles of essential oils of marjoram (Origanum majorana) and oregano (Origanum vulgare) obtained by hydrodistillation and supercritical $\mathrm{CO}_{2}$.
Journal of Essential Oil Research, 29, 367374.

Cao, L., Si, J.Y., Liu, Y. Sun, H., Jin, W., Li, Z., Zhao, X.H., Pan, R.L. (2009). Essential oil composition, antimicrobial and antioxidant properties of Mosla chinensis Maxim. Food Chemistry, 115, 801-805.

Celesti-Grapow, L., Accogli, R. (2010). Flora vascolare alloctona e invasiva delle regioni d'Italia: Università degli Studi di Roma La Sapienza.

Cruciata, M., Gaglio, R., Scatassa, M.L., Sala, G., Cardamone, C., Palmeri, M., Moschetti, G., La Mantia, T., Settanni, L. (2108). Formation and characterization of early bacterial biofilms on different wood typologies applied in dairy production. Applied and Environmental Microbiology 84, e 02107-17.

De Azeredo, G.A., Stamford, T.L.M., Nunes, P.C., Gomes Neto, N.J., De Oliveira, M.E.G., De Souza, E.L. (2011). Combined application of essential oils from Origanum vulgare $\mathrm{L}$. and Rosmarinus officinalis $\mathrm{L}$. to inhibit bacteria and autochthonous microflora associated with minimally processed vegetables. Food Research International, 44, 1541-1548.

de Rapper, S., Viljoen, A., van Vuuren, S. (2016). The In Vitro Antimicrobial Effects of Lavandula angustifolia Essential Oil in Combination with Conventional Antimicrobial Agents. Evidence-Based Complementary and Alternative Medicine, 2752739.

Dellacassa, Eduardo, Lorenzo, Daniel, Moyna, Patrick, Frizzo, Caren D, Serafini, Luciana Atti, \& Dugo, Paola. (1999). Rosmarinus officinalis L.(Labiatae) essential oils from the South of Brazil and Uruguay. Journal of Essential Oil Research, 11(1), 27-30.

Demetzos, C., Perdetzoglou, D.K., Tan, K. (2001). Composition and antimicrobial studies of the oils of Origanum calcaratum Juss. and $O$. scabrum Boiss. et Heldr. from Greece. Journal of Essential Oil Research, 13, 460-462. 
Djeussi, D.E., Noumedem, J.A.K., Seukep, J.A., Fankam, A.G., Voukeng, I.K., Tankeo, S.B., Nkuete, A.H.L., Kuete, V. (2013). Antibacterial activities of selected edible plants extracts against multidrug-resistant Gram-negative bacteria. $B M C$ Complementary and Alternative Medicine, $13,164$.

Figuérédo, G., Chalchat, J.-C., Pasquier, B. (2006). Studies of Mediterranean oregano populations IX: chemical composition of essential oils of seven species of oregano of various origins. Journal of Essential Oil Research, 18, 411-415.

Gaglio, R., Barbera, M., Aleo, A., Lommatzsch, I., La Mantia, T., \& Settanni, L. (2017). Inhibitory Activity and Chemical Characterization of Daucus carota subsp. maximus Essential Oils. Chemistry \& Biodiversity, 14, e1600477.

Gianguzzi, L. (1999). Vegetazione e Bioclimatologia dell'Isola di Pantelleria (Canale de Sicilia). Dipartimento. di Botanica ed Ecologia dell'Università di Camerino.

Giardina, G, Raimondo, F. M., Spadaro, V. (2007). A catalogue of plants growing in Sicily: Herbarium Mediterraneum Panormitanum.

Gurbuz, B., Bagdat, R.B., Uyanik, M., Rezaeieh, K.A.P. (2016). Rosemary (Rosmarinus officinalis L.) cultivation studies under Ankara ecological conditions. Industrial Crops and Products, 88, 12-16.

Han, F., Ma, G.Q., Yang, M., Yan, L., Xiong, W., Shu, J.C., Zhao, Z.D., Xu, H.L. (2017). Chemical composition and antioxidant activities of essential oils from different parts of the oregano. Journal of Zhejiang University: Science B, 18, 79-84.

Hyldgaard, M., Mygind, T., Meyer, R.L. (2012). Essential oils in food preservation: mode of action, synergies, and interactions with food matrix components. Frontiers in Microbiology, 3, 12.

Jan, S., Mir, J.I., Shafi, W., Faktoo, S.Z., Singh, D.B., Wijaya, L., Alyemeni, M.N., Ahmad,
P. (2018). Divergence in tissue-specific expression patterns of genes associated with the terpeniod biosynthesis in two oregano species Origanum vulgare L., and Origanum majorana. Industrial Crops and Products, 123, 546-555.

Kelmanson, J.E., Jager, A.K., van Staden, J. (2000). Zulu medicinal plants with antibacterial activity. Journal of Ethnopharmacology, 69, 241-246.

Kimura, K., Yamaoka, M., Kamisaka, Y. (2006). Inhibition of lipid accumulation and lipid body formation in oleaginous yeast by effective components in spices, carvacrol, eugenol, thymol, and piperine. Journal of Agricultural and Food Chemistry, 54, 35283534.

Klauke, A.L., Racz, I., Pradier, B., Markert, A., Zimmer, A.M., Gertsch, J., Zimmer, A. (2014). The cannabinoid CB(2) receptorselective phytocannabinoid betacaryophyllene exerts analgesic effects in mouse models of inflammatory and neuropathic pain. European Neuropsychopharmacology, 24, 608-620.

Kohiyama, C.Y., Yamamoto Ribeiro, M.M., Mossini, S.A.G., Bando, E., Bomfim, N.D.S., Nerilo, S.B., Rocha, G.H.O., Grespan, R., Mikcha, J.M.G., Machinski, M. (2015). Antifungal properties and inhibitory effects upon aflatoxin production of Thymus vulgaris L. by Aspergillus flavus L. Food Chemistry, 173, 1006-1010.

Kot, B., Wierzchowska, K., Piechota, M., Czerniewicz, P., Chrzanowski, G. (2018). Antimicrobial activity of five essential oils from lamiaceae against multidrug-resistant Staphylococcus aureus. Natural product research, 1-5. (2018). Antimicrobial activity of five essential oils from lamiaceae against multidrug-resistant Staphylococcus aureus. Natural product research, 1-5.

Kunicka-Styczyńska, A. (2011). Activity of essential oils against food-spoiling yeast. A review. Flavour and Fragrance Journal, 26, 326-328. 
La Pergola, A., Restuccia, C., Napoli, E., Bella, S., Brighina, S., Russo, A., Suma, P. (2017). Commercial and wild Sicilian Origanum vulgare essential oils: chemical composition, antimicrobial activity and repellent effects. Journal of Essential Oil Research, 29, 451-460.

Liu, J., Huang, X., Chen, R., Yuan, M. (2017). Efficient bioconversion of high-content volatile fatty acids into microbial lipids by Cryptococcus curvatus ATCC 20509. Bioresource Technology, 239, 394-401.

Militello, M., Settanni, L., Aleo, A., Mammina, C., Moschetti, G., Giammanco, G.M., Blàzquez Amparo, M. Carrubba, A. (2011). Chemical composition and antibacterial potential of Artemisia arborescens L. essential oil. Current Microbiology, 62, 1274-1281.

Najafzadeh, M.J., Sutton, D.A., Keisari, M.S., Zarrinfar, H., de Hoog, G.S., Chowdhary, A., Meis, J.F. (2014). In vitro activities of eight antifungal drugs against 104 environmental and clinical isolates of Aureobasidium pullulans. Antimicrobial Agents and Chemotherapy, 58, 5629-5631.

Napoli, E.M., Curcuruto, G., Ruberto, G. (2010). Screening of the essential oil composition of wild Sicilian thyme. Biochemical Systematics and Ecology, 38, 816-822.

Nguefack, J., Tamgue, O., Dongmo, J.B.L., Dakole, C.D., Leth, V., Vismer, H.F., Amvam Zollo, P.H., Nkengfack, A.E. (2012). Synergistic action between fractions of essential oils from Cymbopogon citratus, Ocimum gratissimum and Thymus vulgaris against Penicillium expansum. Food Control, 23, 377-383.

Nikkhah, M., Hashemi, M., Habibi Najafi, M. B., Farhoosh, R. (2017). Synergistic effects of some essential oils against fungal spoilage on pear fruit. International Journal of Food Microbiology, 257, 285-294.

Nunes, J.M., Bizerra, F.C., e Ferreira, R.C., Colombo, A.L. (2013). Molecular identification, antifungal susceptibility profile, and biofilm formation of clinical and environmental Rhodotorula species isolates. Antimicrobial agents and chemotherapy, 57, 382-389.

Ojeda-Sana, A.M., van Baren, C.M., Elechosa, M.A., Juárez, M.A., Moreno, S. (2013). New insights into antibacterial and antioxidant activities of rosemary essential oils and their main components. Food Control, 31, 189-195.

Ortega-Nieblas, M.M., Robles-Burgueño, M.R., Acedo-Félix, E., González-León, A., Morales-Trejo, A., Vázquez-Moreno, L. (2011). Chemical composition and antimicrobial activity of oregano (Lippia palmeri S. WATS) essential oil. Revista Fitotecnia Mexicana, 34, 11-17.

Palmeira-de-Oliveira, A., Salgueiro, L., Palmeira-de-Oliveira, R., Martinez-deOliveira, J., Pina-Vaz, C., Queiroz, J. A., Rodrigues, A.G. (2009). Anti-Candida activity of essential oils. Mini-Reviews in Medicinal Chemistry, 9, 1292-1305.

Parveen, M., Hasan, M.K., Takahashi, J., Murata, Y., Kitagawa, E., Kodama, O., Iwahashi, H. (2004). Response of Saccharomyces cerevisiae to a monoterpene: evaluation of antifungal potential by DNA microarray analysis. Journal of Antimicrobial Chemotherapy, 54, 46-55.

Pezzani, R., Vitalini, S., Iriti, M. (2017). Bioactivities of Origanum vulgare L.: an update. Phytochemistry reviews, 16, 12531268.

Qvirist, L.A., Filippo, C.D., Strati, F., Stefanini, I., Sordo, M., Andlid, T., Felis, G.E., Mattarelli, P., Cavalieri, D. (2016). Isolation, identification and characterization of yeasts from fermented goat milk of the Yaghnob Valley in Tajikistan. Frontiers in Microbiology, 7, 1690.

Sellami, I.H., Maamouri, E., Chahed, T., Wannes, W.A., Kchouk, M.E., Marzouk, B. (2009). Effect of growth stage on the content and composition of the essential oil and phenolic fraction of sweet marjoram 
(Origanum majorana L.). Industrial Crops and Products, 30, 395-402.

Sezik, E., Tümen, G., Kirimer, N., Özek, T., Baser, K.H.C. (1993). Essential oil composition of four Origanum vulgare subspecies of Anatolian origin. Journal of Essential Oil Research, 5, 425-431.

Swaminathan, B., Gerner-Smidt, P. (2007). The epidemiology of human listeriosis. Microbes Infection, 9, 1236-1243.

Tomei, P.E., Cioni, P.L., Flamini, G., Stefani, A.. (1995). Evaluation of the chemical composition of the essential oils of some Lamiaceae from Serrania de Ronda (Andalucia, Spain). Journal of Essential Oil Research, 7, 279-282.

Tongnuanchan, P., Benjakul, S. (2014). Essential oils: extraction, bioactivities, and their uses for food preservation. Journal of Food Science, 79, R1231-1249.

Tripathy, B., Satyanarayana, S., Khan, K.A., Raja, K. (2017). An Updated Review on Traditional Uses, Taxonomy, Phytochemistry, Pharmacology and Toxicology of Origanum majorana. International Journal of Pharma Research and Health Sciences, 5, 1717-1723.

Tuttolomondo, T., La Bella, S., Licata, M., Virga, G., Leto, C., Saija, A., Trombetta, D., Tomaino, A., Speciale, A., Napoli, E.M., Siracusa, L., Pasquale, A., Curcuruto,
G., Ruberto, G. (2013). Biomolecular characterization of wild sicilian oregano: phytochemical screening of essential oils and extracts, and evaluation of their antioxidant activities. Chemistry and Biodiversity, 10, 411-433.

Viuda-Martos, M., Ruíz-Navajas, Y., Fernández-López, J., Pérez-Álvarez, J.A. (2007). Chemical composition of the essential oils obtained from some spices widely used in Mediterranean region. Acta Chimica Slovenica, 54, 921.

Vuong, C., Otto, M. (2002). Staphylococcus epidermidis infections. Microbes Infect, 4, 481-489.

Wisplinghoff, H., Bischoff, T., Tallent, S.M., Seifert, H., Wenzel, R.P., Edmond, M.B. (2004). Nosocomial bloodstream infections in US hospitals: analysis of 24,179 cases from a prospective nationwide surveillance study. Clinical Infectious Diseases, 39(3), 309-317.

\section{Acknowledgment}

The authors are particularly grateful to Prof. Caterina Mammina, passed away on 2016, for kindly sharing the collection of Listeria monocytogenes when she was alive and to Dr. Alfonso La Rosa for plant identification and the French National Center for Recherche Scientifique (CNRS) - The Etude site in Ecologie Global, Pantelleria, CNRS and the BioDivMex Mistrals program for their support. 